\title{
Project GENESIS: An All-inclusive Model to Perform Cost-Benefit Analysis of Green Roofs and Walls
}

\author{
Cristina Matos Silva ${ }^{1 *}$, Carlos Oliveira Cruz ${ }^{1}$ and Inês Teotónio ${ }^{2}$
}

\begin{abstract}
Green roofs and walls are one of the most promising alternatives for retrofitting existing built environments and tackle urban challenges in a multifunctional way. Yet, these solutions are being confined to specific countries or cities, as their economic contribution has not been fully examined nor accepted. GENESIS is a trans-disciplinary project funded by FCT - Fundação para a Ciência e a Tecnologia that will develop a systematic and comprehensive model to support potential investors or decision-makers, balancing the costs with the benefits of green roofs and walls in a life cycle perspective. The main objective of the project is to enhance existing cost-benefit analysis of green roofs and walls through a multidisciplinary approach that will allow the replication in different regions and type of infrastructures. This will be achieved by: i) monetizing and including all economic, social and environmental benefits in the analysis in order to weight different types of benefits (even those that are typically difficult to estimate because they have no market value) and establish a comparative basis of alternative solutions and potential scenarios; ii) comprising an uncertainty model to cope with climate change and inaccurate forecasting of benefits/costs modelling and; iii) including multi-criteria mode in order to incorporate users and investors preferences. This all-inclusive model crucial for a wide spreading in is green roofs and walls and a more sustainable development in cities.
\end{abstract}

Keywords: green roofs/walls; cost-benefit analysis; investors/users preferences; sustainable urban development; uncertainty

\section{Introduction}

Nature based solutions (NBS), also known as green infrastructures (GI), will play an important role in tackling urban challenges in a multifunctional way. Green roofs/walls are one of the most promising alternatives as they can green the grey infrastructure and value it. Modern green roofs/walls show reliable technology thus additional social and environmental benefits began to gain importance. Examples of green roofs/walls benefits are thermal/energy performance of buildings, water management, biodiversity, aesthetics, air quality, urban heat-island effect and well-being (see more in Berardi et al. (2014) and Vijayaraghavan (2016)). Nevertheless, green roofs/walls have been generally confined to specific cities or countries since these solutions imply additional costs when compared to traditional roof/wall solutions (Carter and Keeler, 2008).

Although there is a perception that green roofs/walls can enhance the economic value of buildings and cities in the long run, their real value is not clear since most studies on their economic merit show high variability and contrasting results (Ascione et al., 2013; Bianchini and Hewage, 2012; Blackhurst et al., 2010; Carter and Keeler, 2008; Niu et al., 2010; Nurmi et al., 2013; Perini and Rosasco, 2016, 2013). The main reasons are:

1'Assistant Professor, Department of Civil Engineering and Architecture and Georesources, CERIS, Instituto Superior Técnico, University of Lisbon, Av. Rovisco Pais, 1049-001 Lisbon, Portugal

${ }^{2} \mathrm{PhD}$ Student, Department of Civil Engineering and Architecture and Georesources, CERIS, Instituto Superior Técnico, University of Lisbon, Av. Rovisco Pais, 1049-001 Lisbon, Portugal

${ }^{*}$ Corresponding Author 
1) It is a challenge to weigh and compare the expected environmental and social benefits with costs. For example, how to balance health improvement from additional green spaces (Clark et al., 2008; Sproul et al., 2014) with installation and maintenance costs (Sproul et al., 2014)?

2) It is difficult to measure the influence of green roofs/walls in each social, environmental and economic benefit. For example, how effective are green roofs in reducing energy consumption of buildings over a certain period of time? There are several available studies for distinct climate but results vary depending on the type of green roof, roof area, number of building floors or expected climate change (Ascione et al., 2013; Jaffal et al., 2012).

3) Private investors and public ones show distinct concerns/preferences (Nurmi et al., 2013; Tomalty et al., 2010). For instance, for a private investor, the impact of the average market value of the real estate is more relevant than the $\mathrm{CO} 2$ reduction. On the other hand, for an Environmental Agency, the latter is more relevant than the former.

4) Effectiveness changes with local conditions because benefits and costs vary according to the climate, local ecology and societal variation. For example, green roofs installation costs are lower in central Europe due to market development (Nurmi et al., 2013) and maintenance costs are lower in cold climate due to higher precipitation and, thus, lower irrigation needs (Ascione et al., 2013).

A wide spreading of green roofs and green walls in cities will happen when their economic merit is generally known and accepted. This implies reliable life cycle costbenefit analyses (CBA) for better informed decision-making and to rank alternative solutions (Adam et al., 2016). Yet, current approaches do not address social, environmental and economic aspects nor the complex relationship between them (European Commission, 2015).

The present article presents project GENESIS - Green roofs / walls ENvironmental and SocIal Savings: Modeling uncertainty and Investors / Users Preferences in allinclusive Cost-Benefit Analysis of Green Roofs / Walls, which was created to fill these identified gaps.

CBA should be regarded as the main methodology to support decision and, therefore, the project adopts the principle of monetizing all relevant impacts, namely environmental and social ones, to allow weighting different types of benefits and establishing a comparative basis of alternative scenarios. Although CBA has been used for several decades, some criticism has emerged particularly regarding the inability to cope with uncertainty in the base assumptions of the analysis (Asplund and Eliasson, 2016). This applies to green roofs/walls since the long-life cycle of these systems makes forecasting extremely inaccurate. Uncertainty can be incorporated using simpler methods, like Monte Carlo Simulation (Burhenne et al., 2013) or more complex approaches using stochastic approaches (Horowitz and Lange, 2014). The inclusion of uncertainty in the model will allow overcoming the difficulties of benefits modelling, benefits comparison as well as climate change. In order to face stakeholders' preferences, a multi-criteria model will determine trade-offs between the different impacts (Marques et al., 2015), using structured interviews and expert's judgement (Barroso et al., 2012; Batista e Silva et al., 2013; Ramos, 2010).

Finally, following the recommendations of European Commission (2015), the proposed 
model will be tested and optimized through four benchmark case studies with a strong replication (i.e., demonstration projects) and validated by expert judgement for encouraging green roofs and walls in buildings/cities. This (all-inclusive) model is a step forward in life cycle costs of green roofs/walls and crucial for a wide spreading of green roofs/walls in buildings/cities.

The present article is divided in three sections. After the introduction, the methodology of project GENESIS is presented in detail, followed by the conclusions.

\section{Methodology}

The purpose of GENESIS is to develop a comprehensive and systematic model for balancing benefits of green roofs/walls with the underlying extra costs, in a life cycle perspective. The main strategy of the project is to enhance CBA of green roofs/walls implementation in different type of infrastructures by developing three major improvements: i) include all environmental, economic and social benefits in the analysis and convert them into monetary units to allow weighting different types of benefits and establishing a comparative basis of alternative scenarios; ii) comprise an uncertainty model to cope with inaccurate forecasting of benefits/costs modelling and climate change; iii) incorporate users/investors preferences through a multi-criteria model.

Given the trans-disciplinary nature of GI, GENESIS project will call upon expertise in estimating green roofs/walls environmental, economic and social benefits and performing accurate CBA. It will count with the participation of practitioners and companies involved in the design, creation and maintenance of green roofs/walls and also investors/owners from private and public sectors (national and international) involved in the case studies, in order to guarantee the validation/usefulness of the proposed model. Their participation in the project will provide data for benchmark case studies with strong up-scaling capacity. An international and national validation is also planned through European Federation of Green Roof (EFB), private and public stakeholders. This multidisciplinary approach will support the proposed cost-benefit model for replication in different regions of the world and type of infrastructure.

From a structure viewpoint, the research project is divided into 4 main tasks, as illustrated in Figure 1.
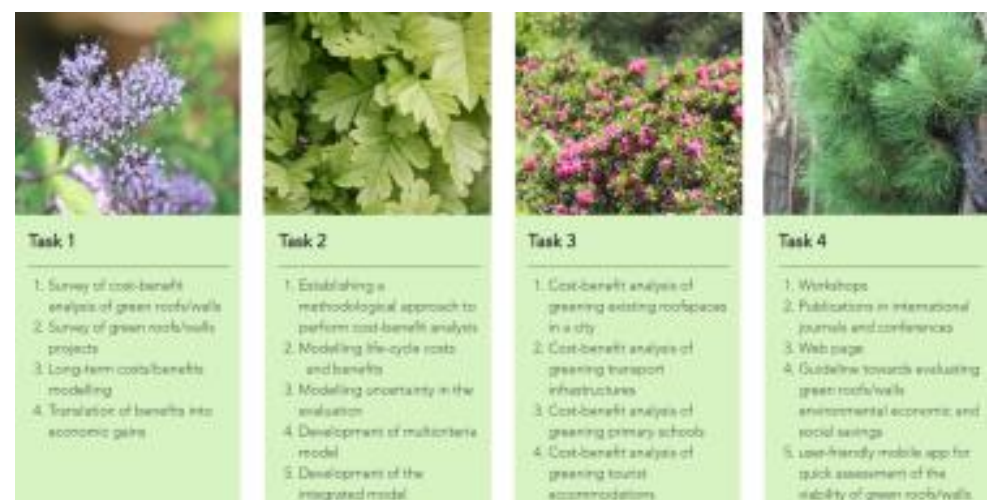

Figure 1. Tasks of Project GENESIS 


\subsection{Task 1 - 'State of the art'}

The project will start with comprehensive state of the art review focused in assessing evidence in a four-stage process. First, survey of past research on CBA of green roofs/walls will assess main conclusions and challenges, highlighting the need of the present research project and give information of gaps that need to be overcome (task 1.1).

Also, a survey of possible interventions with green roofs and walls will be included with the objective of understanding why these GI are being used in each type of infrastructures (task 1.2). The collation of past and ongoing projects will be divided by: type of infrastructure, type of green roof/wall solution and climate, to allow accurate benchmarking. The survey will list the characteristics and main purpose of GI, the costs/benefits measured/estimated, CBA of each case (if available) and total installation cost. This information will be used to complement costs/benefits modelling and to decide plan interventions with GI in the case studies of task 3. Such interactions between tasks are transversal, as represented in Figure 2.

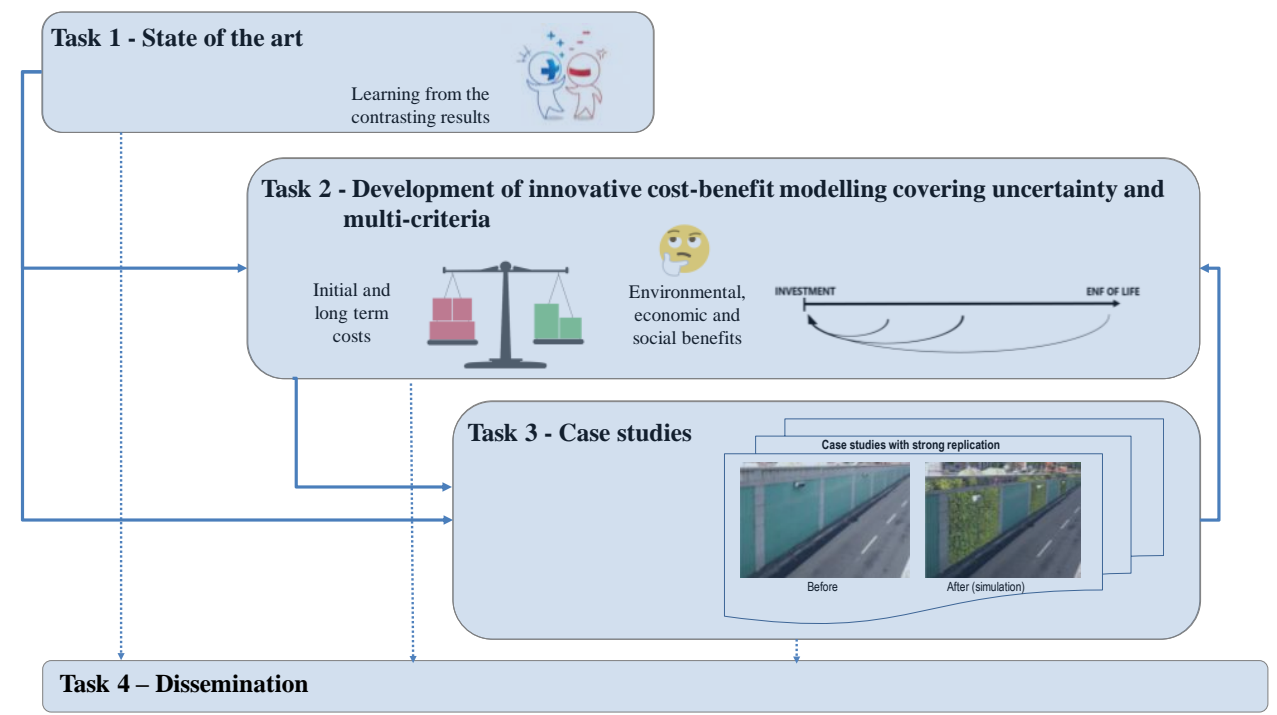

Figure 2. Exchange of information between tasks

Furthermore, task 1 will involve the long-term modelling of costs and benefits of green roofs/walls (task 1.3). The published literature needs to be reviewed in a systematic and unbiased manner with the relevance and quality of the evidence assessed. There is some work already done (e.g. Berardi et al. (2014) but some social benefits such as health, wellbeing, creation of new land and biodiversity are typically not included in CBA. Also, the influence over buildings' commercial value (one of the most significant benefits) is still relatively unknown. Additionally, where knowledge of specific types of benefits is already available, it commonly requires integrating with knowledge regarding other types of benefits. For instance, energy demand of green roofs should also take into account the reduction of heat island effect associated to a large-scale installation of NBS in a city. 
Results will be synthesised and limit values will be defined for each parameter of benefit/cost. The extent to which local environmental or social conditions modifies effectiveness will also be highlighted and discussed.

Lastly, task 1.4 will emphasize ways of converting those limit values of each benefit and co-benefits modelled in the previous task into economic gains. This is is essential when balancing costs and benefits in the long run. For example, the green roofs/walls benefits of reducing pollution, noise and improving health and investment will correspond to a certain value of savings (or negative costs) that can be balanced with the installation and maintenance costs of these GI solutions. An all-inclusive survey and validation of cost/benefits modelling will be ensured by experts and companies' evidence-based practice.

\subsection{Task 2 - 'Development of innovative cost-benefit modelling covering uncertainty and multi-criteria'}

The second task of the project will use the information gathered in task 1 listing all benefits and costs. It is structured in five subtasks (Figure 1). Task 2.1 will be to establish a methodological approach to perform CBA of green roofs and walls in buildings. This evaluation process will adopt an incremental process with 3 levels: financial, economic and socio-environmental. Costs and benefits will be organized in categories, depending on the type of infrastructure under study. Previous studies (Silva et al., 2018; Teotónio et al., 2018) show that benefits can be organized at building and city level, when discussing residential buildings or public spaces, but should be organized according to users, infrastructure and surrounding environment if analyzing transport infrastructures, like stations or roads.

Task 2.2 will use data from task 1.3 to model most significant costs and benefits over time through the definition of adequate models to evaluate the impacts of each type of green roof/wall technology. For example, for the energy efficiency and water drainage simulations, costs and benefits include environmental impacts along the entire life cycle.

The literature has already some work in this area, but the existing level of knowledge is lower regarding co-benefits such as workers productivity, well-being around green spaces and the influence over the commercial value. Whenever necessary, questionnaire procedures (applied to the case studies of task 3) will be conducted to complement upto-date data.

Considering the level of uncertainty surrounding long term analysis, task 2.3 will incorporate uncertainty in the evaluation process. The first approach is to use a simple Monte Carlo simulation-based model, which can be used as a first level of uncertainty analysis (Burhenne et al., 2013). Lately, the intention is to provide more innovative approaches and extend the existing methods towards probabilistic stochastic models (e.g. Cruz and Marques (2012). Therefore, a Bayesian network model will be applied, able to compute the final distribution for the economic net present value (NPV) based on the underlying uncertainty of the main assumptions. The distributions of these assumptions will be estimated based on two alternatives: historical data (for the cases where there is a sufficient and reliable set of past data) and expert's judgment (for the cases where there is not any past information). To incorporate the underlying uncertainty of each of the main assumptions of the model is particularly relevant for those with greater impact on the 
final results. Therefore, the sensibility analysis performed for each case study of task 3 will be useful in the present task.

Additionally, in order to face the fact that there are distinct impacts (environmental, economic or social) for which distinct groups of stakeholders can have a different valuation, a multi-criteria model will be developed to calculate and evaluate the different trade-offs between the different impacts, particularly those dependent on the users/investors preferences (task 2.4). This will involve the determination of an utility function for each of the profiles of the stakeholders (Bianchini and Hewage, 2012; Carter and Keeler, 2008; Claus and Rousseau, 2012). Empirical evidence suggests that each stakeholder will have a distinct assessment of each impact (e.g., Figure 3), e.g., a more or less sensitivity to carbon emissions effect, even though there is not any direct gain associated with a lower carbon emission solution. The calculation of different utility functions in the assessment of GI will be a truly breakthrough in the existing state of the art.

\section{Different stakeholders}

\section{Distinct concerns}
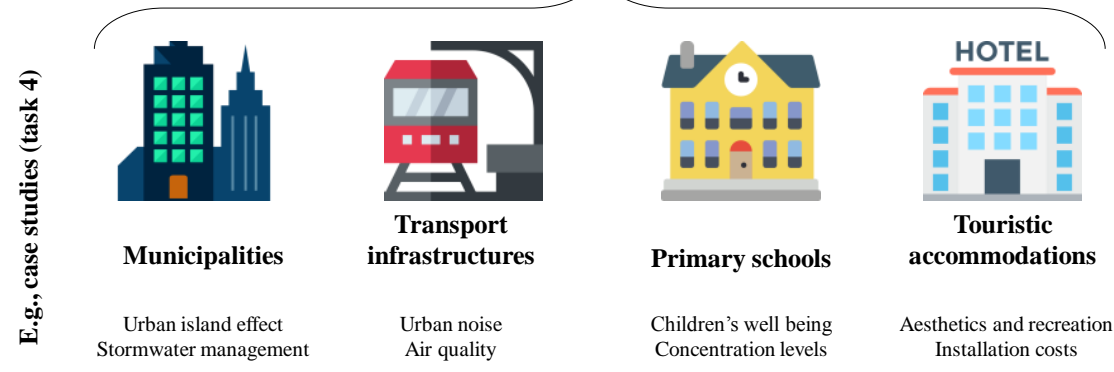

Figure 3. Example of stakeholder's preferences / concerns

The integrated evaluation model developed in task 2.5 will connect the 3 work packages: life cycle cost-benefit model, uncertainty model and multi-criteria model. It is an allinclusive model because no benefits will be neglected, namely environmental and social ones.

\subsection{Task 3 - 'Case studies'}

Task 3 will provide the long-term CBA of green roofs/walls installation in case studies. Tasks 2 and 3 will be developed mostly simultaneously to allow information exchange. Therefore, while task 2 will concentrate on establishing the methodological approach to develop life cycle CBA of green roofs/walls, task 3 will focus in testing the methodology with four complementary benchmark cases. Investors/owners from private and public sectors are identified to participate and four case studies are selected (Table 1), namely: 
Table 1. Selected case studies

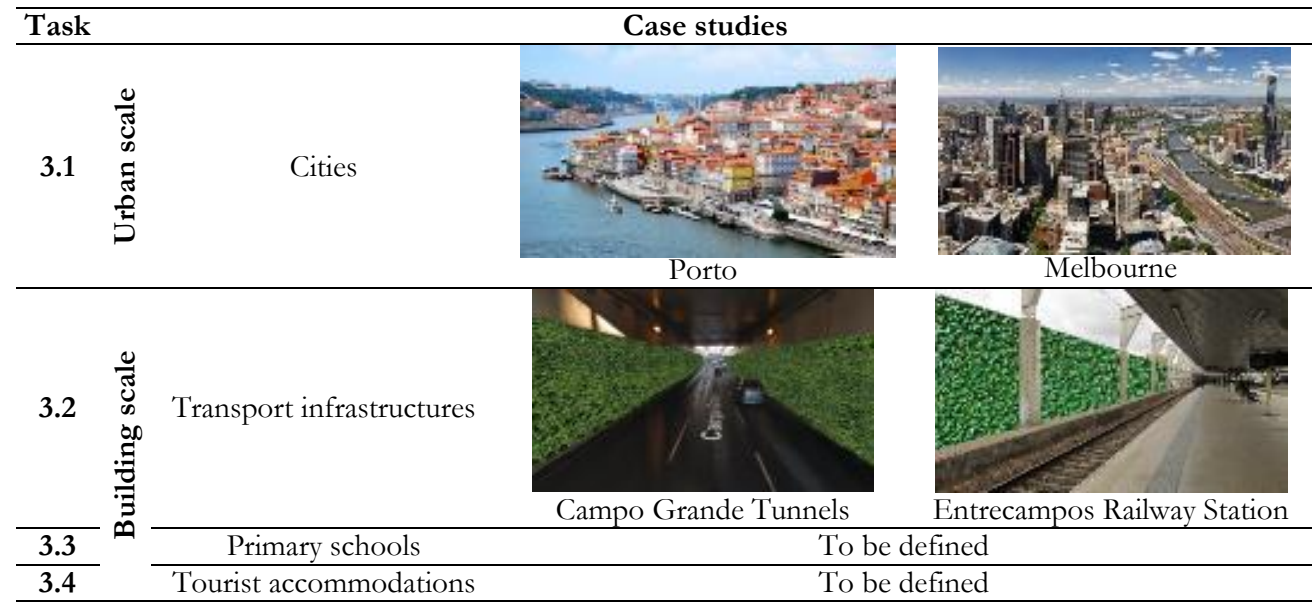

Task 3.1 will study existing roof spaces in two municipalities covering distinct realities (Portugal and Australia). Task 3.2. will study Campo Grande Tunnels in Lisbon, considering the alternative of introducing green roofs decking the underground highway and green walls covering the inner walls of the tunnel. Entrecampos Railway Station in Lisbon will also be analysed. Tasks 3.3 and 3.4 will analyse non-residential buildings in Lisbon. Regarding schools, beneficial association has recently been evidenced between exposure to green space and cognitive development (Dadvand et al., 2015). On the other hand, GI can contribute to a sustainable tourism and tourism might even be added as an advantage to green roofs/walls (Benfield, 2013).

The selection of these four benchmark demonstration projects took into account that: a) they have a strong replication and can work as evidence for encouraging green roofs and walls in cities; b) the most relevant benefits of green roofs/walls vary between them. The methodology of each subtask 3 will start with the characterization of the case study (e.g., buildings, users, problems, opportunities). Such data will be used to forecast the most relevant/probable benefits of GI in each case with the help of the results of task 1.2. Then, for each case study, several scenarios of rehabilitation with GI will be simulated, varying the type of green roof/wall to cover distinct installation/maintenance costs/benefits. Green roofs will be evaluated for the three different types of green roofs (extensive, intensive, semi-intensive) described in (FLL, 2008). Also green walls projects will consider different systems, e.g. climbers or living walls (Manso and Castro-Gomes, 2015). Testing different types of green roofs/walls is essential since benefits/costs vary significantly, e.g. water retention, energy consumption reduction, recreational value (Nardini et al., 2012; Refahi and Talkhabi, 2015) and installation cost (Sproul et al., 2014). Those costs and benefits will be modelled for each scenario according to task 2.2 outputs and converted into monetary values following the recommendations of task 1.4. On one hand, specific benefits such as air quality, heat-island effect, water management, user's well-being/satisfaction and willingness-to-pay will be estimated in detail with the simulation models, comparing performances before and after the installation of GI. In primary schools and touristic accommodations, a small installation area will be 
constructed (prototype) to enhance this step. The results will be compared to the ones from task 1.3. On the other hand, local costs (e.g., installation, maintenance, demolition) will be defined taking into account consultant expert judgement.

The long-term analyses will compare two alternatives: the "do-nothing" option, i.e., maintaining the existing building stock, with the alternative of installing green roofs/walls in the building. The outputs of the CBA will be discussed separately from a financial, economic and socio-environmental point of view, as previously defined.

Although the present model may be applied in different regions of the world, the NPV output of each case study varies depending on local conditions. Therefore, in the four case studies, a sensibility analysis will assess the influence of each cost/benefit variation in the final NPV value in order to complement the integrated model of task 2 (namely subtask 2.3) and point out the key parameters to focus on in future research.

\subsection{Task 4 - 'Dissemination and outputs'}

The project considers different actions to promote effective scientific and general diffusion. A specific task involving is defined for dissemination, to assure that inputs from different stakeholders are taken into account and that the model and case studies spread out. The project web page https://www.projectgenesis-ist.com/ accepts comments and contributions from all visitants, even non-expert users to assure that the final model is actually all-inclusive. Also, the project will produce a guideline towards evaluating green roofs/walls environmental economic and social savings. This is a critical output, because the existing state of the art does not provide any tool for policy makers, investors or users, to evaluate the potential benefits of using green systems. Finally, despite the complexity of the evaluation model, the project will prepare a simple, user friendly mobile app, that can be used for a quick assessment of the viability of green roofs/walls. This will be a fundamental dissemination tool, because it will be directed not just to academics but most importantly to the society. The objective is that it can be used by any non-expert user.

\section{Conclusions/ Targets}

Both owners and designers point to the lack of effective models as a reliable tool in the feasibility of green roofs/walls. Overall, GENESIS research project will improve the decision-making process of using NBS as a mechanism towards a more sustainable management of existing (scarce) resources in the built environment.

The output of GENESIS will enable decision makers (e.g. users, owners, governments) to make robust and informed decisions regarding the real economic value of green roofs/walls solutions. This is crucial to the success of this type of solutions. Additionally, the evaluation tool proposed in this project can help to design effective incentive mechanisms able to significantly leverage the large-scale development of such systems. The four case studies were chosen to have a strong replication and work as benchmark projects, proving the added value of green roofs/walls. 


\section{Acknowledgements}

This work is supported by the FCT - Fundação para a Ciência e a Tecnologia through Project GENESIS, reference PTDC/GES-URB/29444/2017.

\section{References}

Adam, K., Hoolohan, V., Gooding, J., Knowland, T., Bale, C.S.E., Tomlin, A.S., 2016. Methodologies for city-scale assessment of renewable energy generation potential to inform strategic energy infrastructure investment. Cities 54, 45-56. https://doi.org/10.1016/j.cities.2015.10.015

Ascione, F., Bianco, N., de' Rossi, F., Turni, G., Vanoli, G.P., 2013. Green roofs in European climates. Are effective solutions for the energy savings in air-conditioning? Appl. Energy 104, 845-859. https://doi.org/10.1016/j.apenergy.2012.11.068

Asplund, D., Eliasson, J., 2016. Does uncertainty make cost-benefit analyses pointless? Transp. Res. Part A Policy Pract. 92, 195-205. https://doi.org/10.1016/j.tra.2016.08.002

Barroso, F.L., Pinto-Correia, T., Ramos, I.L., Surová, D., Menezes, H., 2012. Dealing with landscape fuzziness in user preference studies: Photo-based questionnaires in the Mediterranean context. Landsc. Urban Plan. 104, 329-342. https://doi.org/10.1016/j.landurbplan.2011.11.005

Batista e Silva, J., da Graça Saraiva, M., Loupa Ramos, I., Bernardo, F., 2013. Improving Visual Attractiveness to Enhance City-River Integration-A Methodological Approach for Ongoing Evaluation. Plan. Pract. Res. 28, 163-185. https://doi.org/10.1080/02697459.2012.704734

Benfield, R.W., 2013. Garden Tourism. CAB International.

Berardi, U., GhaffarianHoseini, A., GhaffarianHoseini, A., 2014. State-of-the-art analysis of the environmental benefits of green roofs. Appl. Energy 115, 411-428. https://doi.org/10.1016/j.apenergy.2013.10.047

Bianchini, F., Hewage, K., 2012. Probabilistic social cost-benefit analysis for green roofs: A lifecycle approach. Build. Environ. 58, 152-162. https://doi.org/10.1016/j.buildenv.2012.07.005

Blackhurst, M., Hendrickson, C., Asce, D.M., Matthews, H.S., Asce, A.M., 2010. Cost-Effectiveness of Green Roofs. J. Archit. Eng. 16, 136-143. https://doi.org/10.1061/(ASCE)AE.19435568.0000022

Burhenne, S., Tsvetkova, O., Jacob, D., Henze, G.P., Wagner, A., 2013. Uncertainty quantification for combined building performance and cost-benefit analyses. Build. Environ. 62, 143-154. https://doi.org/10.1016/j.buildenv.2013.01.013

Carter, T., Keeler, A., 2008. Life-cycle cost-benefit analysis of extensive vegetated roof systems. J. Environ. Manage. 87, 350-363. https://doi.org/10.1016/j.jenvman.2007.01.024

Clark, C., Adriaens, P., Talbot, F.B., 2008. Green roof valuation: A probabilistic economic analysis of environmental benefits. Environ. Sci. Technol. 42, 2155-2161. https://doi.org/10.1021/es0706652

Claus, K., Rousseau, S., 2012. Public versus private incentives to invest in green roofs: A cost benefit analysis for Flanders. Urban For. Urban Green. 11, 417-425. https://doi.org/10.1016/j.ufug.2012.07.003

Cruz, C.O., Marques, R.C., 2012. Using Probabilistic Methods to Estimate the Public Sector Comparator. Comput. Civ. Infrastruct. Eng. 27, 782-800. https://doi.org/10.1111/j.1467-8667.2012.00771.x

Dadvand, P., Nieuwenhuijsen, M.J., Esnaola, M., Forns, J., Basagaña, X., Alvarez-Pedrerol, M., Rivas, I., López-Vicente, M., De Castro Pascual, M., Su, J., Jerrett, M., Querol, X., Sunyer, J., 2015. Green spaces and cognitive development in primary schoolchildren. Proc. Natl. Acad. Sci. 112, 79377942. https://doi.org/10.1073/pnas.1503402112

European Commission, 2015. Towards an EU Research and Innovation policy agenda for Nature-Based Solutions \& Re-Naturing Cities. https://doi.org/10.2777/765301

FLL, 2008. Guidelines for the Planning, Construction and Maintenance of Green Roofing - Green Roofing Guideline.

Horowitz, J., Lange, A., 2014. Cost-benefit analysis under uncertainty - A note on Weitzman's dismal theorem. Energy Econ. 42, 201-203. https://doi.org/10.1016/j.eneco.2013.12.013 
Jaffal, I., Ouldboukhitine, S.-E., Belarbi, R., 2012. A comprehensive study of the impact of green roofs on building energy performance. Renew. Energy 43, 157-164. https://doi.org/10.1016/j.renene.2011.12.004

Manso, M., Castro-Gomes, J., 2015. Green wall systems: A review of their characteristics. Renew. Sustain. Energy Rev. 41, 863-871. https://doi.org/10.1016/j.rser.2014.07.203

Marques, R.C., da Cruz, N.F., Pires, J., 2015. Measuring the sustainability of urban water services. Environ. Sci. Policy 54, 142-151. https://doi.org/10.1016/j.envsci.2015.07.003

Nardini, A., Andri, S., Crasso, M., 2012. Influence of substrate depth and vegetation type on temperature and water runoff mitigation by extensive green roofs: Shrubs versus herbaceous plants. Urban Ecosyst. 15, 697-708. https://doi.org/10.1007/s11252-011-0220-5

Niu, H., Clark, C., Zhou, J., Adriaens, P., 2010. Scaling of Economic Benefits from Green Roof Implementation in Washington, DC. Environ. Sci. Technol. 44, 4302-4308. https://doi.org/10.1021/es902456x

Nurmi, V., Votsis, A., Perrels, A., Lehvävirta, S., 2013. Cost-benefit analysis of green roofs in urban areas : case study in Helsinki. Helsinki.

Perini, K., Rosasco, P., 2016. Is greening the building envelope economically sustainable? An analysis to evaluate the advantages of economy of scope of vertical greening systems and green roofs. Urban For. Urban Green. 20, 328-337. https://doi.org/10.1016/j.ufug.2016.08.002

Perini, K., Rosasco, P., 2013. Cost-benefit analysis for green facades and living wall systems. Build. Environ. 70, 110-121. https://doi.org/10.1016/j.buildenv.2013.08.012

Ramos, I.L., 2010. "Exploratory landscape scenarios" in the formulation of "landscape quality objectives." Futures 42, 682-692. https://doi.org/10.1016/j.futures.2010.04.005

Refahi, A.H., Talkhabi, H., 2015. Investigating the effective factors on the reduction of energy consumption in residential buildings with green roofs. Renew. Energy 80, 595-603. https://doi.org/10.1016/j.renene.2015.02.030

Silva, C.M., Serro, J., Ferreira, P.D., Teotónio, I., 2018. The Socio-Economic Feasibility of Greening Rail Stations: A Case Study in Lisbon. Eng. Econ. 2701, 1-41. https://doi.org/10.1080/0013791X.2018.1470272

Sproul, J., Wan, M.P., Mandel, B.H., Rosenfeld, A.H., 2014. Economic comparison of white, green, and black flat roofs in the United States. Energy Build. 71, 20-27. https://doi.org/10.1016/j.enbuild.2013.11.058

Teotónio, I., Silva, C.M., Cruz, C.O., 2018. Eco-solutions for urban environments regeneration: The economic value of green roofs. J. Clean. Prod. Manuscr. Accept. Publ.

Tomalty, R., Komorowski, B., Doiron, D., 2010. The Monetary Value of the Soft Benefits of Green Roofs 114.

Vijayaraghavan, K., 2016. Green roofs : A critical review on the role of components, benefits, limitations and trends. Renew. Sustain. Energy Rev. 57, 740-752. https://doi.org/10.1016/j.rser.2015.12.119 